\title{
Students' Self-Assessment of Modern Making Skills
}

\section{Dr. Diana R. Haidar, Carnegie Mellon University}

Diana R. Haidar, Ph.D. is an Assistant Teaching Professor in the Department of Mechanical Engineering at Carnegie Mellon University. Her background spans industry work in manufacturing, research efforts towards developing nanocomposites for advanced tribological performance in extreme environments, and prototyping experience designing-fabricating-building-testing-implementing various custom experimental equipment. These experiences led to a passion for using makerspace resources to bring more hands-on design experiences to the classroom, which she applies to her position as Educational Director as she leads efforts in the new Maker Ecosystem. She focuses her efforts on connecting students across engineering and the broader university to the physical, digital, and intellectual resources in TechSpark. In addition to her leadership and teaching roles, she enjoys promoting diversity in STEM through youth outreach activities.

\section{Dr. Michael C. Melville, Carnegie Mellon University}

Michael Melville works as a Data Science Research Associate at Carnegie Mellon University's Eberly Center for Teaching Excellence and Educational Innovation, where he consults with faculty, graduate students, and post-docs to design, implement, and assess research projects that relate to teaching and learning in their classrooms. He also contributes to a variety of program-level assessment projects on the CMU campus. Mike's training includes an M.A. and Ph.D. in Social Psychology from the University of New Hampshire, as well as an M.Ed. in sport and performance psychology from Springfield College. His interests include the science of learning, research methodology, and data analysis. Prior to joining the Eberly Center in 2017, Mike worked as the Teaching and Learning Research Coordinator at the Center for Excellence and Innovation in Teaching and Learning at the University of New Hampshire. 


\title{
Students' Self-Assessment of Modern Making Skills
}

\begin{abstract}
Many studies have examined the effects of active learning on students' educational outcomes. For engineers, this often comes in the form of fabricating components for proof-of-concept prototypes of their engineering designs. At Carnegie Mellon University, the general engineering students in the freshmen course Fundamentals of Mechanical Engineering prepare for engineering design projects by receiving training in the modern making skills of CAD software, 3D printing, laser cutting-engraving, power tools, and Arduino. This study analyzed the selfassessment of students' confidence level to apply these maker skills before and after completing the course. Results showed a significant improvement in students' self-efficacy for applying these skills after completing the course. Furthermore, a notable number of students expressing doubt in their abilities to complete a particular task with a maker skill had improvements to their self-efficacy upon noting the steps towards successful completion of that task, and expressed confidence in completing an even more complex task.
\end{abstract}

\section{Introduction}

Engineering educators are often interested in knowing whether their students can confidently apply the skills they were taught from coursework. In many studies, exams and final grades are used as the key metrics in measuring students' success towards applying theory to practice [1][5]. Yet, other researchers have repeatedly taken more interest in variables such as self-efficacy to determine students' motivations and outcomes [6]-[8]. Bandura defined self-efficacy as "an individuals' judgment of their capability to organize and execute courses of action for a given task" [9]. In a similar tone, Speier and Frese refer to self-efficacy as "notion that one can bring about positive results through one's own actions" [10]. The indicators of self-efficacy are generally based on students' self-assessment of their confidence level to accomplish a task using a Likert-type scale [6]-[8]. There is a rich research literature suggesting the importance of selfefficacy in predicting academic success, as well as persistence [9], [11]. Engineering fields have received specific attention in the literature as self-efficacy has been identified as an important factor in predicting student outcomes [12], [13].

Engineering also represents an interesting domain in terms of academic self-efficacy because success in engineering often requires not only academic ability in the traditional sense (i.e., to learn and perform well in a course), but also the ability to actually make products successfully. Several fields of engineering at Carnegie Mellon University have a heavy focus on the latter ability, and that is the ability explored here. This paper investigates elements of self-efficacy in a freshman engineering course that is founded not just on students' ability to learn concepts, but also to plan and execute tasks with accuracy. In Fundamentals of Mechanical Engineering, students are taught modern making skills to enable them to create proof-of-concept prototypes of their engineering designs. Historically, mechanical engineering students across the US, as well as many globally, develop functional prototypes for their senior capstone project. At Carnegie Mellon University, students in the Department of Mechanical Engineering conduct prototyping in at least one core course each year of their undergraduate career. 
The safe and correct use of rapid fabrication equipment is taught individually through hands-on training in class and directed practice outside of class. Students were surveyed before and after completion of the course to self-assess their ability to apply modern making skills in the areas of CAD software, 3D printing, laser cutting-engraving, power tools, and Arduino. The selfassessment was used to study students' perceptions of whether they believe themselves capable of actually executing tasks for each maker skill, in addition to understanding the concepts they're based on. Research questions included:

1. After completing the course, do students express confidence in applying each maker skill individually towards a corresponding exemplary task?

2. Is the level of confidence that students have in their abilities to apply maker skills improved after taking the course?

3. In cases where students express doubt or negativity in their ability to use maker skills in task completion, at which point in the process of that task is there a break down in confidence?

The following sections will present the method used to survey students, results of the surveys, and discuss the outcomes of this study.

\section{Method}

Participants were $(n=130)$ undergraduate students enrolled in an engineering course called 'Fundamentals of Mechanical Engineering.' This is a survey course typically taken by first-year general engineering students in the College of Engineering at Carnegie Mellon University. Although this course is a graduation requirement for mechanical engineering students, it is an optional course for all non-mechanical engineering students to satisfy a graduation requirement of introductory coursework from an alternate department.

Participants were administered a brief electronic survey on the first day of recitation before initiating teaching maker skills. Students were asked to indicate their ability to make a series of products that utilized five different skills that were going to be taught in the course. These skills were categorized as CAD software (CAD), 3D printing (PRINT), laser cutting-engraving (LASER), using hand power tools (TOOLS), and Arduino (ARDUINO). For each skill, participants were shown a picture of a product and asked to indicate whether they thought they currently had the ability to make what was shown in the picture (see Question 1 in Figures 1-5). Responses were recorded on a three point scale, ("Yes, definitely" I can do that; "Maybe" I can do that; "No" I cannot do that). These responses were posed to measure students' confidence towards completion of the exemplary task, thereby identifying students' self-efficacy. The contents and results of the pre-course survey were not mentioned nor discussed with the students.

After the last class of the semester, the students were sent a link to a post-course survey that asked them to once again indicate their ability to make a series of products using the same five skills that were mentioned on the first survey. For each skill, the same item from the first survey was shown, along with the same three-point response scale. This time, however, after indicating whether they had the ability make what was shown in the picture, they were shown three consecutive images depicting the individual steps that are necessary to create the final product shown in the initial picture. For each step, the students were asked whether they had the ability 
to do what was being depicted using the same three-point scale (see Questions 2-4 in Figures 1-5). The purpose of adding questions that segmented the major task was seeking students' perceived barriers in the cases where a student was not certain whether they could make the item in question. After being shown the three steps for each product, students were shown a product with more complexity than the original item they were shown for that category, and asked to indicate whether they thought they could make the more complex item using the same threepoint scale (see Question 5 in Figures 1-5). This final question was included to provide an identifier for students who were confident in learning and applying maker skills beyond the coursework. Completion of both surveys was optional, and only data from students who completed both the pre-course survey and post-course survey was used, which was a total of 29 participants. All results were deidentified and aggregated after the semester was over and the course had been completed. 


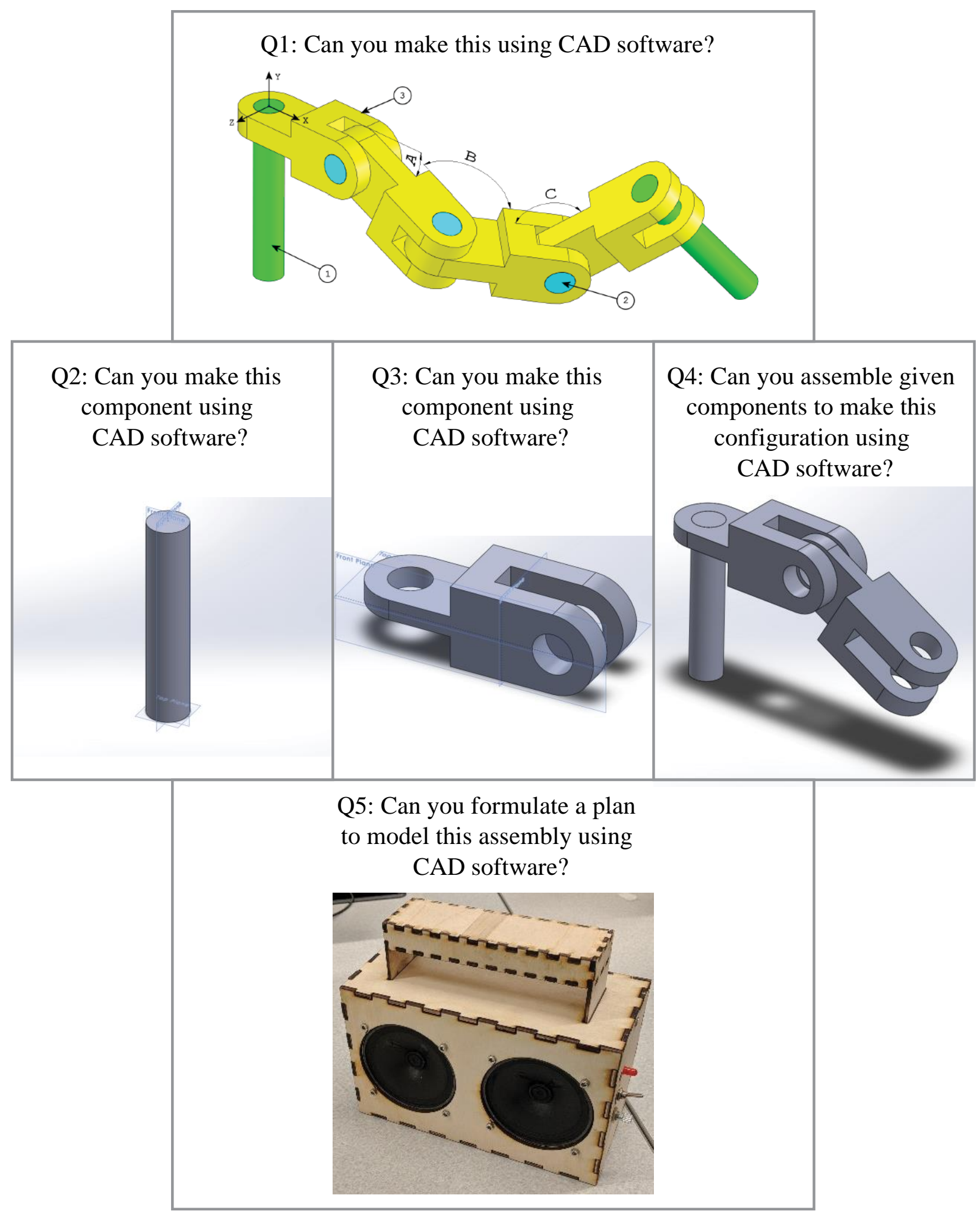

Figure 1: Participants were asked the following questions with the accompanying images (CAD). Question 1 was included on the pre-course and post-course survey, whereas Questions 2-5 were only on the post-course survey. 


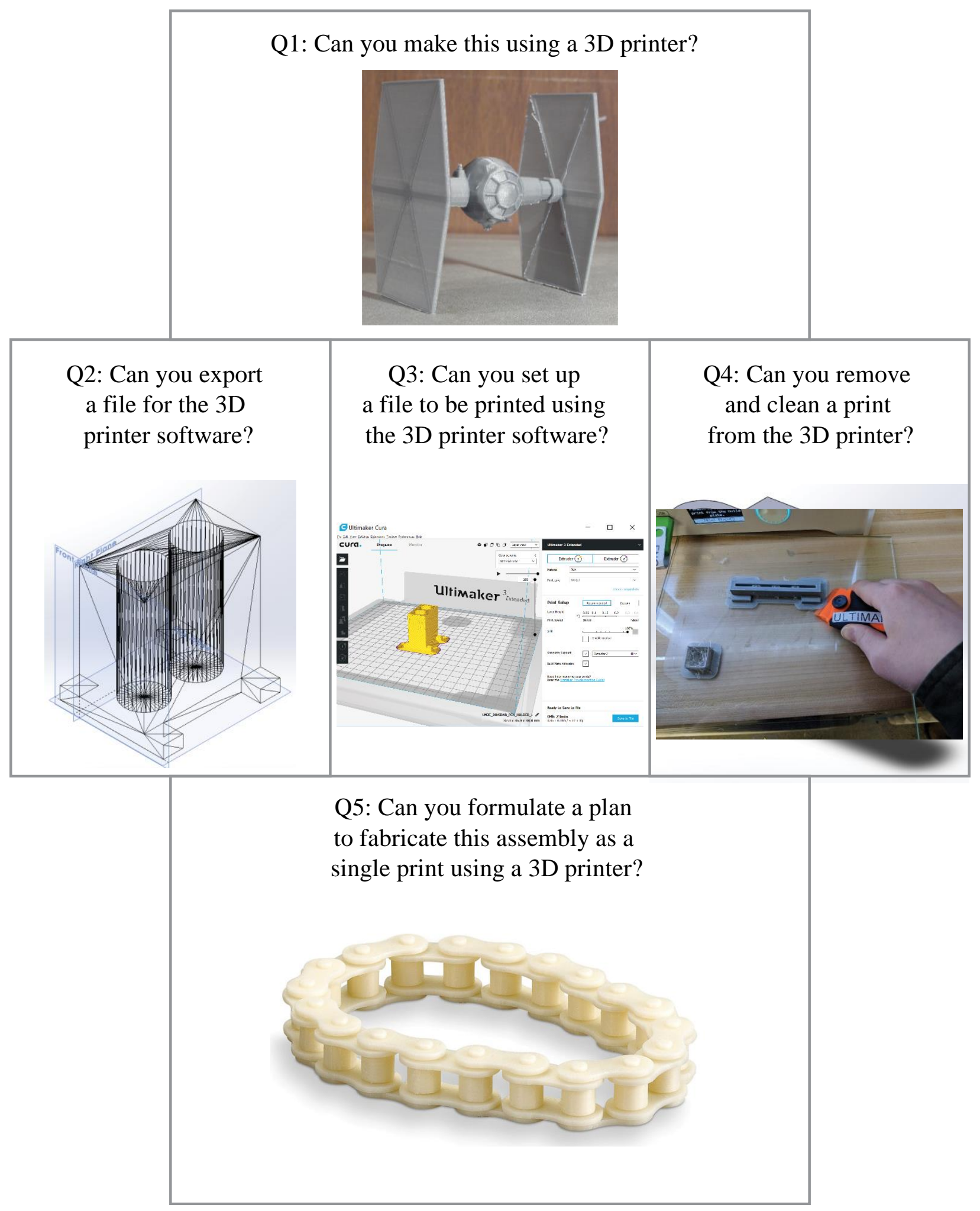

Figure 2: Participants were asked the following questions with the accompanying images (PRINT). Question 1 was included on the pre-course and post-course survey, whereas Questions 2-5 were only on the post-course survey. 


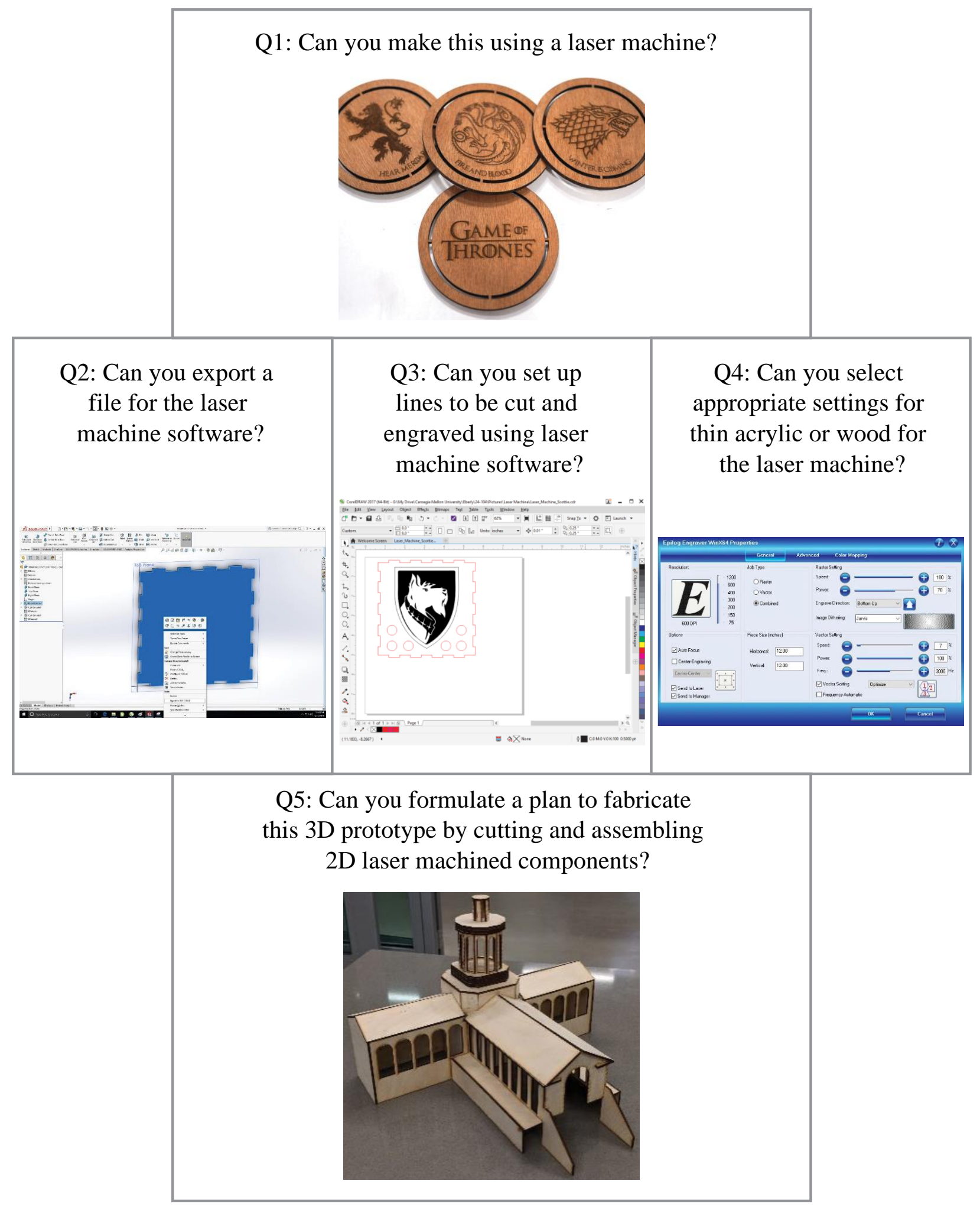

Figure 3: Participants were asked the following questions with the accompanying images (LASER). Question 1 was included on the pre-course and post-course survey, whereas Questions 2-5 were only on the post-course survey. 


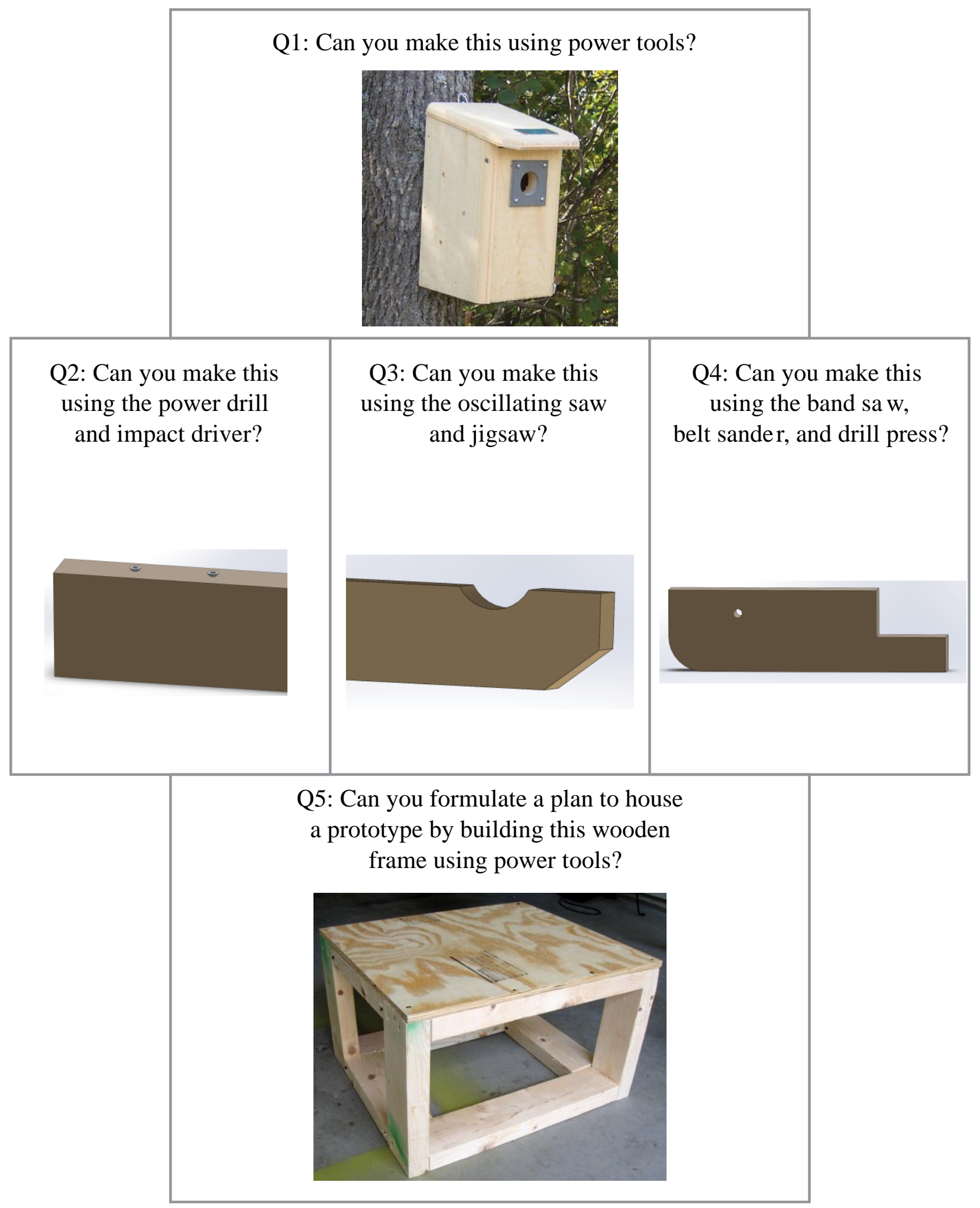

Figure 4: Participants were asked the following questions with the accompanying images (TOOLS). Question 1 was included on the pre-course and post-course survey, whereas Questions 2-5 were only on the post-course survey. 


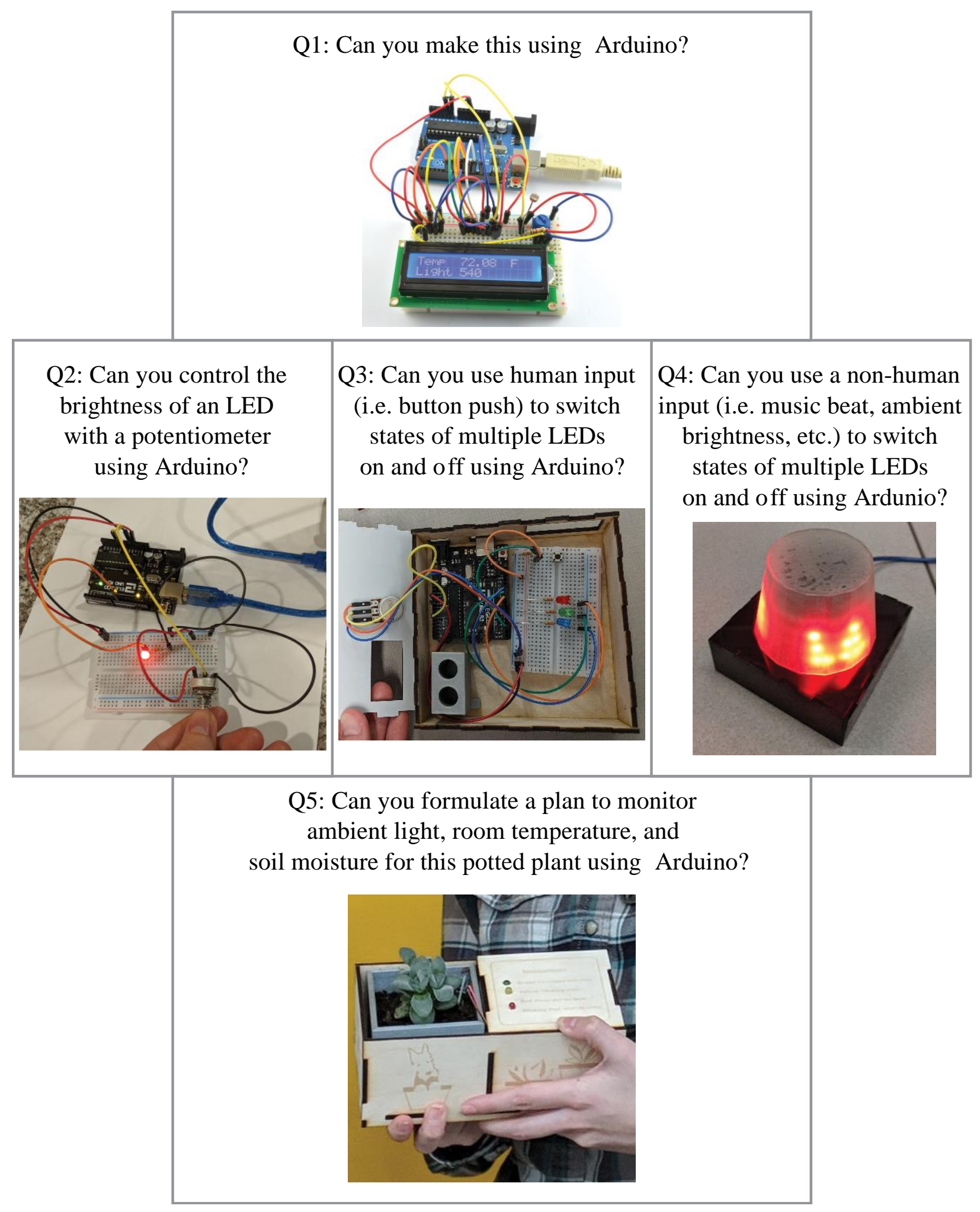

Figure 5: Participants were asked the following questions with the accompanying images (ARDUINO). Question 1 was included on the pre-course and post-course survey, whereas Questions 2-5 were only on the post-course survey. 


\section{Results}

Pre-course survey data was collected from 29 students that gave five ratings per person, one for each skill category, for a total of 145 ratings. Data was tabulated to create a percentage of the students that indicated "Yes, definitely," "No," or "Maybe" for each of the five products representing a skill category (see Question 1 in Figures 1-5). The frequency of responses for the products representing the individual skill groups are depicted in Figure 6. These results were also tabulated collapsing across products to create a total overall percentage of student ratings that were yes, no, or maybe (see Appendix Table 2). Before the course began, only about $30 \%$ of students' collective responses indicated they could definitely make the products in question across all of the skill groups. This value came from higher frequency of confidence response "Yes" for power tools (45\%) and laser machines (38\%), and equally lower frequency of confidence "Yes" for CAD, 3D printing, and Arduino (each 21\%). In contrast, nearly 50\% of students' responses in each skills category indicated they could not make the product in question. This represented four of the five skills, with the exception of power tools, which had only $10 \%$ of responses indicate that they could not make the product in question.

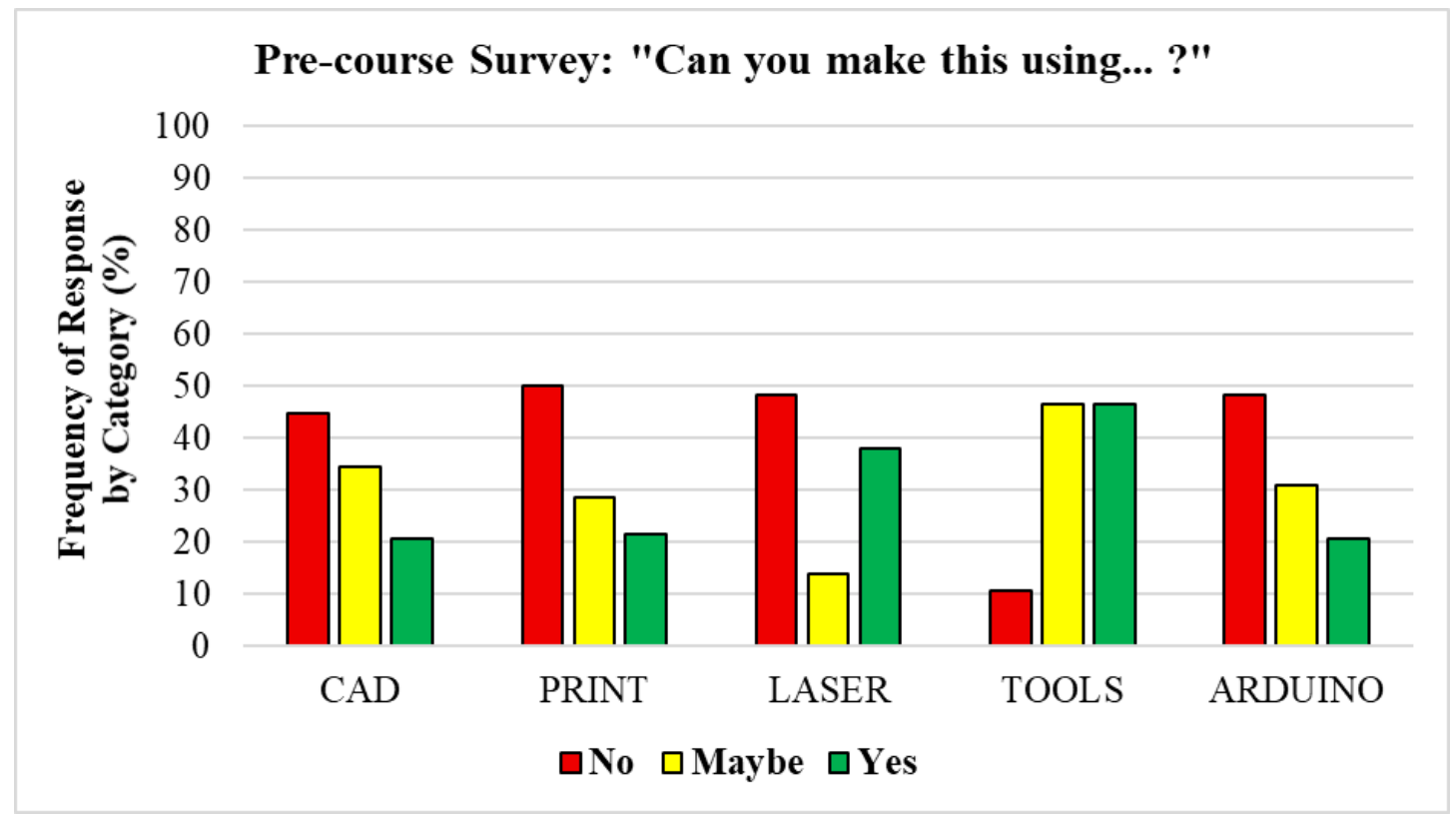

Figure 6: Frequency of responses on the pre-course survey indicating students' belief in their ability to make a specific product using a particular skill. Students reported highest frequency of "Yes" for the power tools category, and nearly equal frequency of lowest confidence "No" for the other four of five categories.

The post-course survey data was tabulated in an identical fashion to the pre-course survey data. The frequency of responses for the products representing the individual skill groups are depicted in Figure 7. These results also underwent tabulation by collapsing across products to create a total overall percentage of student ratings that were yes, no, or maybe (see Appendix Table 3). Post-course results showed marked improvement over pre-course results of students' perceptions 
regarding their ability to make the products that appeared on the pre-course survey (see Question 1 in Figures 1-5). After the course was complete, about $60 \%$ of students indicated that they could definitely make the products in question across all of the skill groups. Confident responses were highest for laser cutting-engraving (86\%) and lowest for Arduino and 3D printing (each $35 \%$ ). Negative responses had the opposite trend of frequency rating; the overall number of the "No" response on the post-course survey dropped to only $8 \%$. Perhaps most importantly, for each individual skill, both the rate of the "Yes" response increased and the rate of the "No" response decreased from the pre-course survey several times over.

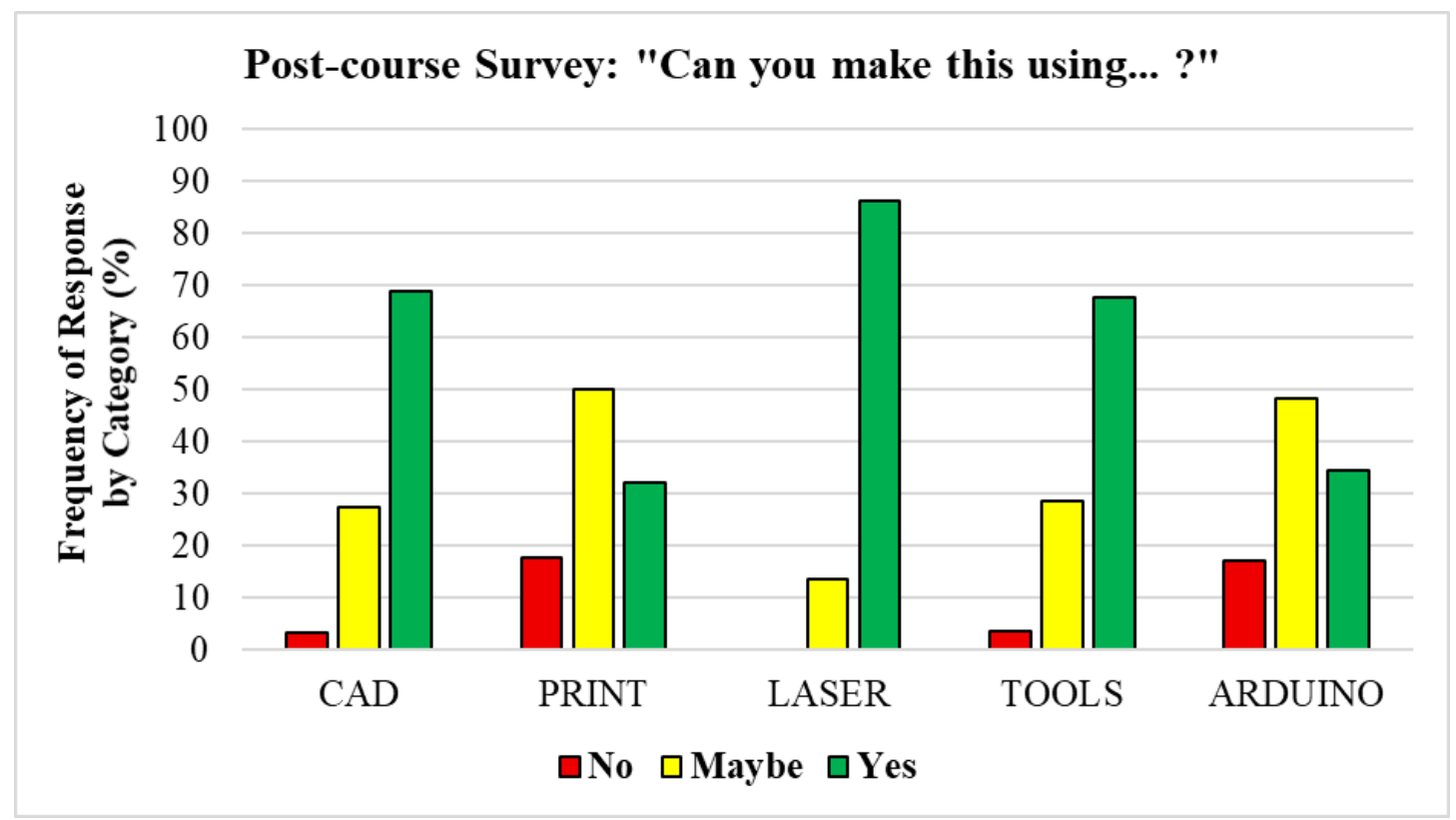

Figure 7: Frequency of responses on the post-course survey indicating students' belief in their ability to make a specific product using a particular skill. Students reported highest frequency of "Yes" for laser machines, and lowest frequency of "Yes" for 3D printing and Arduino. The least confident response "No" was the minority of responses for each of the five categories.

To examine improvement on the student level, results on the post-course survey were tabulated as conditional based on what each student indicated on the pre-course survey. Improvement was defined as migrating responses moving towards more confident from "No" to "Maybe" or "Yes," otherwise "Maybe" to "Yes." The breakdown of students' responses that were improved from the pre-course to post-course survey are depicted in Figure 8. These migrations towards improvement made up the majority of responses by students, with $50 \%$ of students originally indicating "No" later responding "Yes" and nearly $60 \%$ of students originally indicating "Maybe" later responding "Yes" (see Appendix Table 5). 


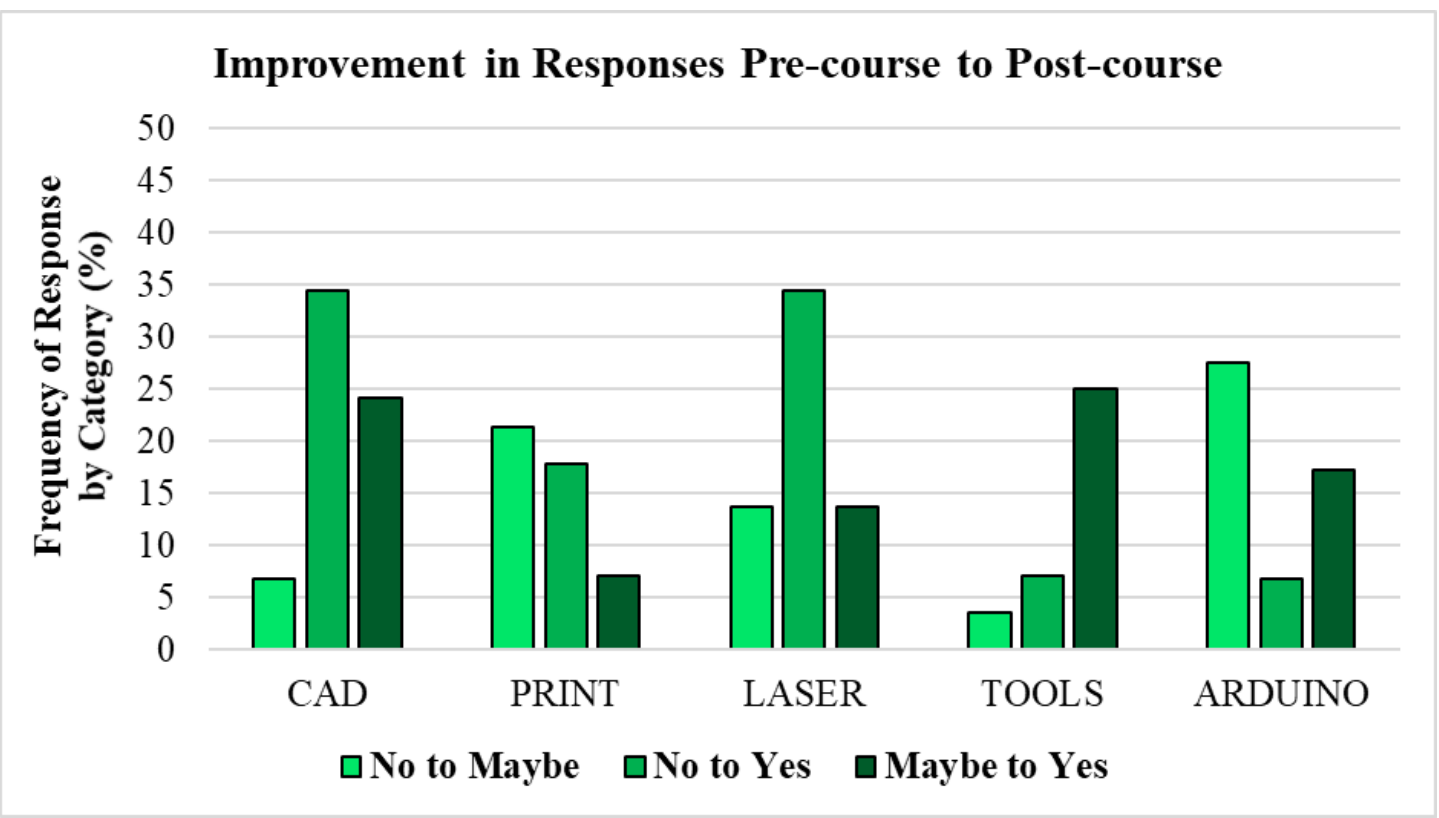

Figure 8: Pre-course to post-course migration of students' survey responses that were improvements in confidence. These students indicated an increased belief in their ability to make a specific product using a particular skill.

In addition to indicating their perceived ability to make the specific products for each skill category on the post-course survey, students were also shown a series of three images of progressive steps that were the essential components of making each product in question (see Questions 2-4 in Figures 1-5). For each of the steps, the students were asked the same question regarding whether they thought they were able to complete the task depicted in the image. In order to discern the perceived barriers to making each product, these responses were examined for all students who did not indicate confidence that they could make a particular product on the post-course survey (i.e., responded either "Maybe" or "No"). The results in Table 1 show that in three of the five categories, over half of these students indicated no barriers towards task completion. 
Table 1: Summary of post-course survey results for students having answered of "No" or "Maybe" on Question 1 for any of the particular skills. These students then identified their barriers to completing that task in Questions 2-4. Finally, these students were asked whether they had confidence in completing an even more complex task with that particular skill in Question 5. Cell quantities represent total response frequencies. A notable number of students identified no barriers to completing the original task and reported confidence in completing the more complex project.

\begin{tabular}{|c|c|c|c|c|c|}
\hline Category & $\begin{array}{c}\text { Total } \\
\text { "no/maybe" } \\
\text { Q1 }\end{array}$ & $\begin{array}{c}\text { At least one } \\
\text { barrier } \\
\text { Q2/Q3/Q4 }\end{array}$ & $\begin{array}{c}\text { No barriers } \\
\text { indicated } \\
\text { Q2/Q3/Q4 }\end{array}$ & $\begin{array}{c}\text { Total } \\
\text { "no/maybe" } \\
\text { Q5 }\end{array}$ & $\begin{array}{c}\text { Total } \\
\text { "yes, definitely" } \\
\text { Q5 }\end{array}$ \\
\hline CAD & 9 & 2 & 7 & 5 & 4 \\
\hline PRINT & 20 & 8 & 12 & 16 & 4 \\
\hline LASER & 4 & 4 & 0 & 3 & 1 \\
\hline TOOLS & 10 & 4 & 6 & 3 & 7 \\
\hline ARDUINO & 19 & 19 & 0 & 18 & 1 \\
\hline
\end{tabular}

Finally, after viewing the series of progressive steps for component skills in each category, students were shown a product with decidedly more complexity than the original product shown for that skill category (see Question 5 in Figures 1-5). Students were again asked to indicate whether they thought they could make each of the more complex products (see Appendix Table 4). For students that did not indicate confidence on the post-course survey to complete the easier task (Question 1), each category had at least one unexpected response of confidence to complete the more complex task (Question 5). Moreover, three of the five categories ranged from 20-70\% of the students originally responding without confidence for the easier task then indicated confidence for the more complex task. 


\section{Discussion}

The primary goal of teaching engineering students modern making skills is to prepare them for conducting projects that require proof-of-concept prototypes of their engineering designs. To impart these skills, all students individually participated in hands-on experiences, both through training in class and directed practice outside of class. Surveys were created to provide instructors insight into the confidence level of students to apply maker skills in the five categories of CAD, 3D printing, laser cutting-engraving, power tools, and Arduino.

For instructors teaching modern making, there was a desire to know whether students expressed confidence in applying each of the five skills after completing the course. In an ideal situation for those instructors, every student would have answered "Yes, definitely" for each of the five products representing a skill category on the post-course survey (see Question 1 in Figures 1-5). In actuality, the post-course survey results in Figure 7 showed that each of the five maker skill areas had some students answering "No" I cannot complete the task or "Maybe" I can complete the task. Perhaps more importantly, results showed the post-course response "Yes" was the largest population by more than double for three of five categories, and a relatively close second to "Maybe" in the other two categories. These post-course responses were a major positive difference over the nearly $50 \%$ of all students in the pre-course survey indicating "No" in four of five categories depicted in Figure 6. In a more detailed analysis of the overall migration of answers between pre-course and post-course surveys, these positive changes were quantifiable. Results in Figure 8 showed a strong improvement to self-efficacy overall with $86 \%$ of all responses to the collective of Questions 1 starting as "No" moved upwards to "Maybe" or "Yes" (see Appendix Table 5). Another significant increase in self-efficacy overall was the migration of responses of those originally responding "Maybe," 58\% moved upwards to "Yes" while the remaining $42 \%$ confirmed their original status of "Maybe. Hence, there is a clear trend of improvement for students' self-assessed confidence in applying all five categories of maker skills after completing the course.

A key component of continuous improvement for instructors is recognizing students' barriers, identified here as expressing doubt or negativity towards applying maker skills. With this knowledge, instructors are informed in adjusting the course material to mitigate or remove those barriers. For students to have accurately responded "No" or "Maybe" to Question 1 on the postcourse survey for any of the five maker skills, there should be a lack of confidence in conducting at least one of the main steps towards completing that task. Due to this, it was expected that there would be at least one point of break down in the chain of product completion steps shown by Questions 2, 3, and 4, which would be signified as not answering "Yes" to at least one of those three questions.

For students that expressed doubt or negativity on Question 1 regarding the three categories CAD, PRINT, and TOOLS, a clear majority of them also reported confidence in their ability to conduct all three major steps in the process of using that maker skill (i.e. those students answered "Yes" to Questions 2, 3, and 4). One interpretation of this result is the majority of students answering "No" or "Maybe" to Question 1 made an incorrect initial response (i.e. they actually believe themselves capable of completing the task), which means they should actually have 
answered "Yes" to Question 1. Another interpretation is that answering Questions 2-4 caused a positive change in their self-efficacy. Bandura and Schunk have noted that people tend to identify lower self-efficacy for distal goals (i.e. those being larger and further to achieve) compared to higher self-efficacy for proximal goals (i.e. those being smaller and nearer to achieve) [14]. By analogy, the distal goal of Question 1 was segmented into proximal goals of Questions 2-4, thereby increasing those students' self-efficacy to respond "Yes" to all three questions. There is additional support for the interpretation that answering Questions 2-4 caused a positive change in those students' self-efficacy from an investigation by Stock and Cervone, who found that upon achieving proximal goals, people identify higher self-efficacy for future goal attainment [15]. Finally, this interpretation is supported by the results of Question 5, a task notably more difficult due to higher complexity than Question 1, had a significant number of confident "Yes" responses in each of these three categories.

\section{Conclusion}

This paper analyzed the self-assessment of general engineering students in a freshmen course to apply modern making skills: CAD software, 3D printing, laser cutting-engraving, power tools, and Arduino. Results suggest that students had major improvements in self-efficacy for applying these skills towards task completion after completing the course. For students expressing doubt or negativity in their ability to use maker skills in task completion, a significant proportion indicated no barriers towards conducting all the steps towards successfully completing that task. In addition, there is evidence that some students may have had improvements to self-efficacy during the post-course survey, by claiming confidence in completing a more complex task after noting the steps towards simpler task completion with the same maker skill.

\section{References}

[1] M. Prince, "Does Active Learning Work? A Review of the Research," J. Eng. Educ., vol. 93, no. 3, pp. 223-231, Jul. 2004.

[2] K. L. Ruhl, C. A. Hughes, and P. J. Schloss, "Using the Pause Procedure to Enhance Lecture Recall," Teach. Educ. Spec. Educ., vol. 10, no. 1, pp. 14-18, Jan. 1987.

[3] R. R. Hake, "Interactive-engagement versus traditional methods: A six-thousand-student survey of mechanics test data for introductory physics courses," Am. J. Phys., vol. 66, no. 1, pp. 64-74, Jan. 1998.

[4] D. Roberts P.E. and D. R. Haidar, "Manipulation Matters: Isolating the Impact of Lecture vs. Lab Experience in an Undergraduate Engineering Controls Class," presented at the 2017 ASEE Annual Conference \& Exposition, 2017.

[5] F. Chowdhury, "The Power of Using Pause Procedure During Accounting Lecture: An Action Research Study," Eur. J. Bus. Soc. Sci., vol. 5, no. 6, pp. 101-108, Oct. 2016.

[6] F. Pajares, "Self-Efficacy Beliefs in Academic Settings," Rev. Educ. Res., vol. 66, no. 4, pp. 543-578, Dec. 1996.

[7] M. A. Hutchison, D. K. Follman, M. Sumpter, and G. M. Bodner, "Factors Influencing the Self-Efficacy Beliefs of First-Year Engineering Students," J. Eng. Educ., vol. 95, no. 1, pp. 39-47, 2006.

[8] A. R. Carberry, H.-S. Lee, and M. W. Ohland, "Measuring Engineering Design SelfEfficacy," J. Eng. Educ., vol. 99, no. 1, pp. 71-79, 2010. 
[9] A. Bandura, Self-efficacy: The exercise of control. New York, NY, US: W H Freeman/Times Books/ Henry Holt \& Co, 1997.

[10] C. Speier and Mi. Frese, "Generalized Self Efficacy As a Mediator and Moderator Between Control and Complexity at Work and Personal Initiative: A Longitudinal Field Study in East Germany," Hum. Perform., vol. 10, no. 2, pp. 171-192, Jun. 1997.

[11] M. Besterfield-Sacre, C. J. Atman, and L. J. Shuman, "Characteristics of Freshman Engineering Students: Models for Determining Student Attrition in Engineering," J. Eng. Educ., vol. 86, no. 2, pp. 139-149, 1997.

[12] P.-H. Hsieh, J. R. Sullivan, D. A. Sass, and N. S. Guerra, "Undergraduate Engineering Students' Beliefs, Coping Strategies, and Academic Performance: An Evaluation of Theoretical Models," J. Exp. Educ., vol. 80, no. 2, pp. 196-218, 2012.

[13] M. K. Ponton, J. H. Edmister, L. S. Ukeiley, and J. M. Seiner, "Understanding the Role of Self-Efficacy in Engineering Education," J. Eng. Educ., vol. 90, no. 2, pp. 247-251, 2001.

[14] A. Bandura and D. H. Schunk, "Cultivating competence, self-efficacy, and intrinsic interest through proximal self-motivation," J. Pers. Soc. Psychol., vol. 41, no. 3, pp. 586$598,1981$.

[15] J. Stock and D. Cervone, "Proximal goal-setting and self-regulatory processes," Cogn. Ther. Res., vol. 14, no. 5, pp. 483-498, Oct. 1990. 


\section{Appendix}

Table 2: Frequency of responses on the pre-course survey indicating students' belief in their ability to make a specific product using a particular skill. Students reported highest frequency of "Yes" for the power tools category, and nearly equal frequency of lowest confidence "No" for the other four of five categories. Cell quantities represent the number of students having a given response and that quantity as a percentage of the total group indicated in parentheses.

\begin{tabular}{|c|c|c|c|c|c|c|}
\hline Pre-course & CAD & PRINT & LASER & TOOLS & ARDUINO & TOTALS \\
\hline No & $13(45 \%)$ & $14(48 \%)$ & $14(48 \%)$ & $3(10 \%)$ & $14(48 \%)$ & $58(40 \%)$ \\
\hline Maybe & $10(34 \%)$ & $9(31 \%)$ & $4(14 \%)$ & $13(45 \%)$ & $9(31 \%)$ & $45(31 \%)$ \\
\hline Yes & $6(21 \%)$ & $6(21 \%)$ & $11(38 \%)$ & $13(45 \%)$ & $6(21 \%)$ & $42(29 \%)$ \\
\hline
\end{tabular}

Table 3: Frequency of responses on the post-course survey indicating students' belief in their ability to make a specific product using a particular skill. Students reported highest frequency of "Yes" for laser machines, and lowest frequency of "Yes" for 3D printing and Arduino. The least confident response "No" was the minority of responses for each of the five categories. Cell quantities represent the number of students having a given response and that quantity as a percentage of the total group indicated in parentheses.

\begin{tabular}{|c|c|c|c|c|c|c|}
\hline Post-course & CAD & PRINT & LASER & TOOLS & ARDUINO & TOTALS \\
\hline No & $1(3 \%)$ & $5(17 \%)$ & $0(0 \%)$ & $1(3 \%)$ & $5(17 \%)$ & $12(8 \%)$ \\
\hline Maybe & $8(28 \%)$ & $14(48 \%)$ & $4(14 \%)$ & $9(31 \%)$ & $14(48 \%)$ & $49(34 \%)$ \\
\hline Yes & $20(69 \%)$ & $10(35 \%)$ & $25(86 \%)$ & $19(66 \%)$ & $10(35 \%)$ & $84(58 \%)$ \\
\hline
\end{tabular}


Table 4: Summary of post-course survey results for students having answered of "No" or "Maybe" on Question 1 for any of the particular skills. These students then identified their barriers to completing that task in Questions 2-4. Finally, these students were asked in Question 5 whether they had confidence in completing an even more complex task with that particular skill. A notable number of these students identified no barriers to completing the original task and reported confidence in completing the more complex project. Cell quantities represent total response frequencies.

\begin{tabular}{|c|c|c|c|c|c|c|c|}
\hline Category & $\begin{array}{c}\text { Total } \\
\text { "no/maybe" } \\
\text { Q1 }\end{array}$ & $\begin{array}{c}\text { One } \\
\text { Barrier } \\
\text { Q2/Q3/Q44 }\end{array}$ & $\begin{array}{c}\text { Two } \\
\text { Barriers } \\
\text { Q2/Q3/Q4 }\end{array}$ & $\begin{array}{c}\text { Three } \\
\text { Barriers } \\
\text { Q2/Q3/Q4 }\end{array}$ & $\begin{array}{c}\text { No barriers } \\
\text { indicated } \\
\text { Q2/Q3/Q4 }\end{array}$ & $\begin{array}{c}\text { Total } \\
\text { "no/maybe" } \\
\text { Q5 }\end{array}$ & $\begin{array}{c}\text { Total "yes, } \\
\text { definitely" } \\
\text { Q5 }\end{array}$ \\
\hline CAD & 9 & 0 & 0 & 2 & 7 & 5 & 4 \\
\hline PRINT & 20 & 3 & 4 & 1 & 12 & 16 & 4 \\
\hline LASER & 4 & 2 & 1 & 1 & 0 & 3 & 1 \\
\hline TOOLS & 10 & 1 & 2 & 1 & 6 & 3 & 7 \\
\hline ARDUINO & 19 & 4 & 5 & 10 & 0 & 18 & 1 \\
\hline
\end{tabular}




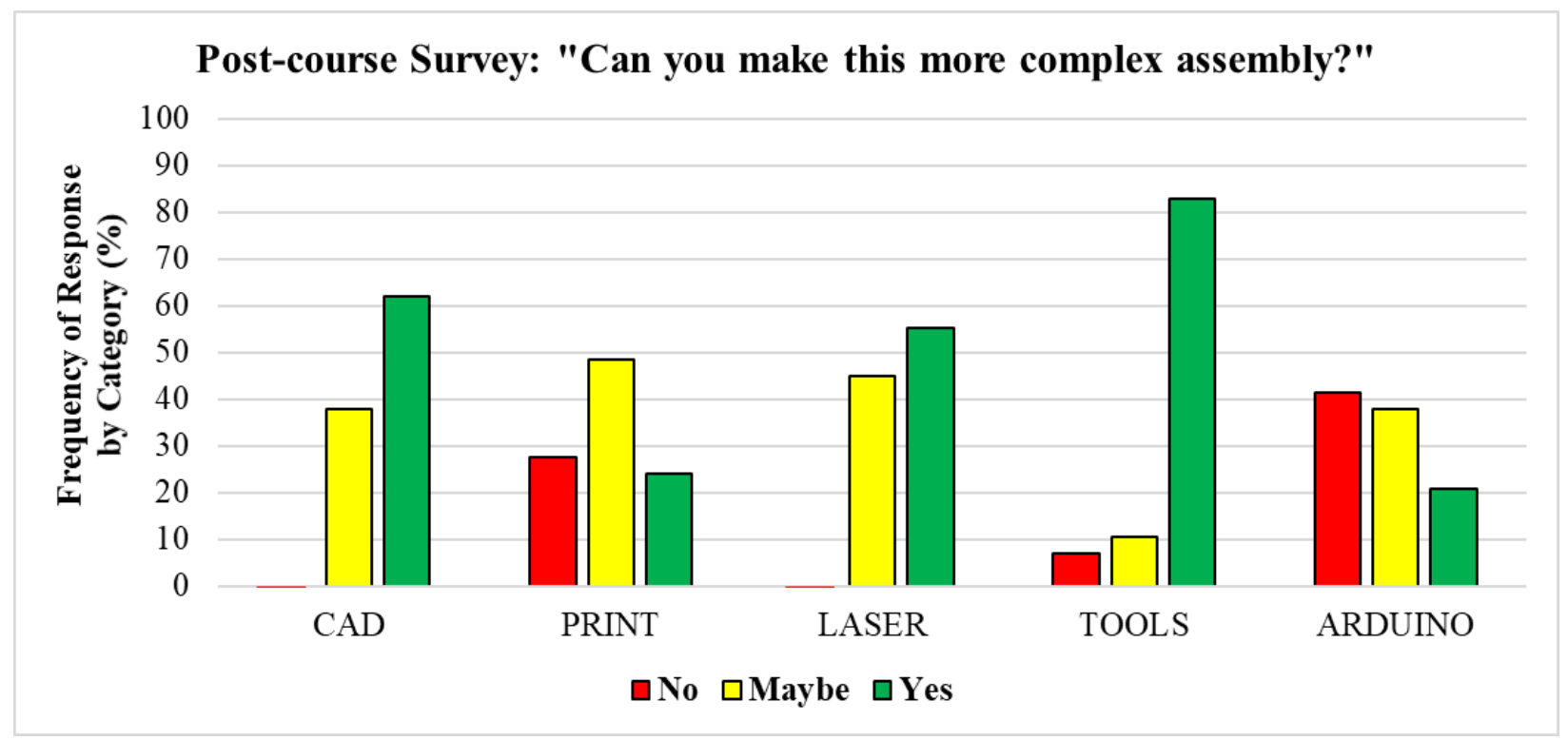

Figure 9: Frequency of responses on the post-course survey in Question 5, which indicated students' belief in their ability to complete an even more complex task with that particular skill.

Table 5: Collapsed skills summary of response migration from pre-course to post-course survey. Cell quantities represent the number of students having a given response and that quantity as a percentage of the total group indicated in parentheses.

\begin{tabular}{|l|c|c|c|}
\cline { 2 - 4 } \multicolumn{1}{c|}{} & \multicolumn{3}{c|}{ Pre-course Response } \\
\hline Post Response & NO & MAYBE & YES \\
\hline$-->$ to no & $8(14 \%)$ & 0 & $4(10 \%)$ \\
\hline$-->$ to maybe & $21(36 \%)$ & $19(42 \%)$ & $9(21 \%)$ \\
\hline$-->$ to yes & $29(50 \%)$ & $26(58 \%)$ & $29(69 \%)$ \\
\hline
\end{tabular}


Table 6: Individual skills summary of response migration from pre-course to post-course survey. Cell quantities represent the number of students having a given response and that quantity as a percentage of the total group indicated in parentheses.

\begin{tabular}{|l|c|c|c|}
\cline { 2 - 4 } \multicolumn{1}{c|}{} & \multicolumn{3}{c|}{ CAD Pre-course Survey } \\
\hline Post Response & NO & MAYBE & YES \\
\hline$-->$ to no & $1(3 \%)$ & 0 & 0 \\
\hline$-->$ to maybe & $2(7 \%)$ & $3(10 \%)$ & $3(10 \%)$ \\
\hline$-->$ to yes & $10(34 \%)$ & $7(24 \%)$ & $3(10 \%)$ \\
\hline
\end{tabular}

\begin{tabular}{|l|c|c|c|}
\cline { 2 - 4 } \multicolumn{1}{c|}{} & \multicolumn{3}{c|}{ PRINT Pre-course } \\
\hline Post Response & NO & MAYBE & YES \\
\hline$-->$ to no & $3(10 \%)$ & 0 & $2(7 \%)$ \\
\hline$-->$ to maybe & $6(21 \%)$ & $6(21 \%)$ & $2(7 \%)$ \\
\hline$-->$ to yes & $5(17 \%)$ & $3(10 \%)$ & $2(7 \%)$ \\
\hline
\end{tabular}

\begin{tabular}{|l|c|c|c|}
\cline { 2 - 4 } \multicolumn{1}{c|}{} & \multicolumn{3}{c|}{ LASER Pre-course } \\
\hline Post Response & NO & MAYBE & YES \\
\hline$-->$ to no & 0 & 0 & 0 \\
\hline$-->$ to maybe & $4(14 \%)$ & 0 & 0 \\
\hline$-->$ to yes & $10(34 \%)$ & $4(14 \%)$ & $11(38 \%)$ \\
\hline
\end{tabular}

\begin{tabular}{|l|c|c|c|}
\cline { 2 - 4 } \multicolumn{1}{c|}{} & \multicolumn{3}{c|}{ TOOLS Pre-course } \\
\hline Post Response & NO & MAYBE & YES \\
\hline$-->$ to no & 0 & 0 & $1(3 \%)$ \\
\hline$-->$ to maybe & $1(3 \%)$ & $6(21 \%)$ & $2(7 \%)$ \\
\hline$-->$ to yes & $2(7 \%)$ & $7(24 \%)$ & $10(34 \%)$ \\
\hline
\end{tabular}


Table 6 continued

\begin{tabular}{|l|c|c|c|}
\cline { 2 - 4 } \multicolumn{1}{c|}{} & \multicolumn{3}{c|}{ ARDUINO Pre-course } \\
\hline Post Response & NO & MAYBE & YES \\
\hline$-->$ to no & $4(14 \%)$ & 0 & $1(3 \%)$ \\
\hline$-->$ to maybe & $8(28 \%)$ & $4(14 \%)$ & $2(7 \%)$ \\
\hline$-->$ to yes & $2(7 \%)$ & $5(17 \%)$ & $3(10 \%)$ \\
\hline
\end{tabular}

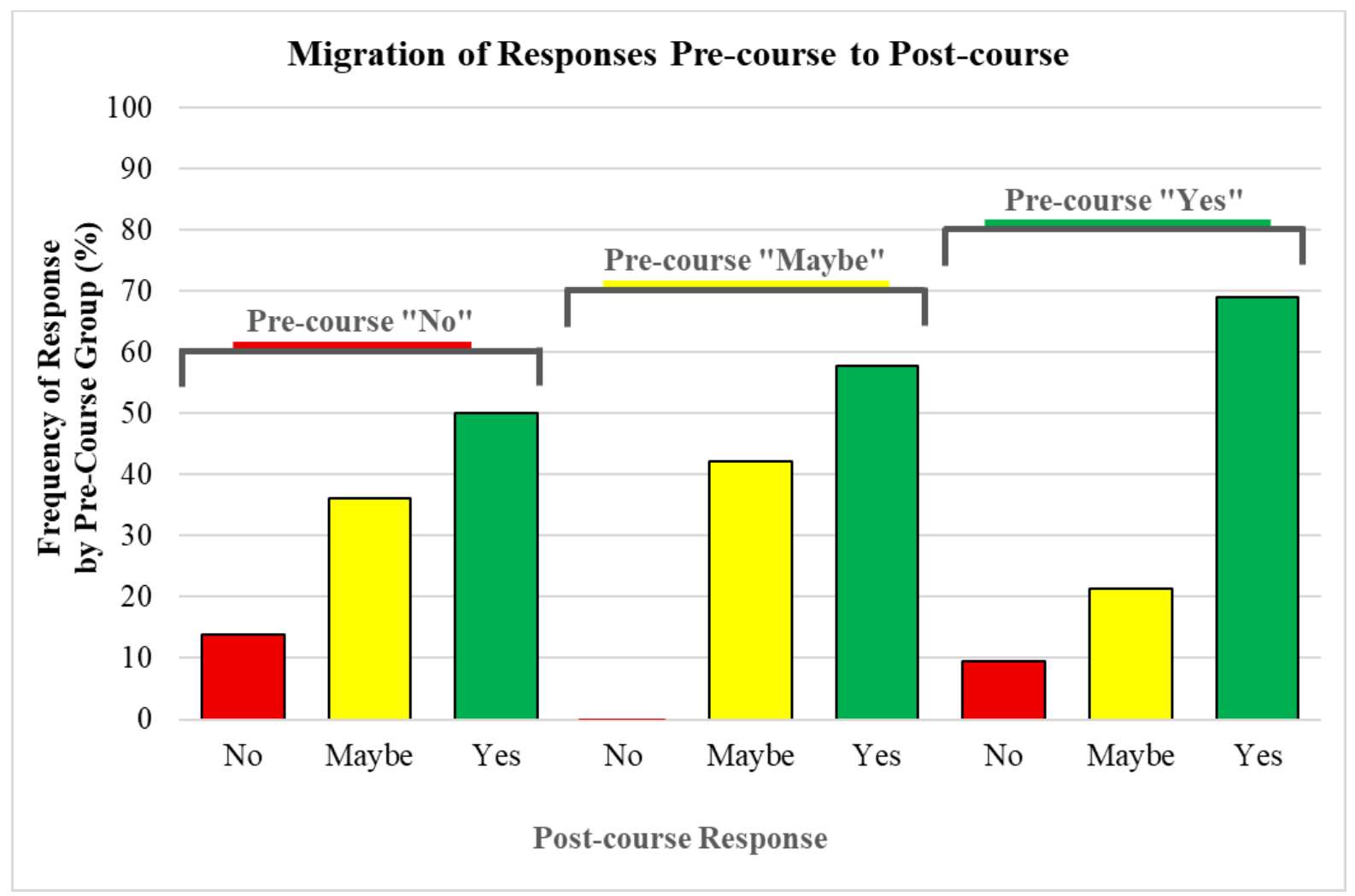

Figure 10: Frequency of response migration for individual skills from pre-course to post-course survey, which indicates change in students' belief in their ability to make a specific product using a particular skill. 